\section{Challenges of Maternal and Prenatal Care in Nigeria}

\section{Abstract}

Background and aim: Evidence in the literature indicates that maternal health care by a skilled birth attendant is one of the key strategies for maternal survival. However, the rate of maternity care utilization and reduction of maternal death is very low in Nigeria. This study was designed to explored factors influencing women utilization of maternal and prenatal care in Nigeria. Hence, the need to understand factors that serves as barriers to accessing maternal and prenatal care in Nigeria using the Socio-ecological Model (SEM).

Methods: A mixed method was employed for this study. Data collection used questionnaires and in-depth interviews. Questionnaires were distributed to 330 respondents of which 318 of them were retrieved and qualitative in-depth interviews were conducted for 6 participants. The study was conducted in one of the tertiary health facilities in Nigeria, amongst mothers aged 15-45 years. Statistical Package for Social Sciences (SPSS) was used in analyzing the quantitative data whilst a qualitative content analysis was done for the qualitative data.

Results: The study established that education, income level, costs associated with seeking care, distance and time taken to travel were significantly associated with maternity health care services utilization. The study concludes that; costs of treatment, distance and time, income level, staff attitude and women's autonomy were critical in determining women utilization of maternity care services.

Keywords: Challenges; Maternal; Prenatal; Care; Nigeria
Mandu Stephen

Ekpenyong*, Carol Bond and David Matheson

\section{Department of Public Health, Faculty of Education, University of Wolverhampton, United Kingdom}

*Corresponding author:

Mandu Stephen Ekpenyong

ほ ladyekpenyong@gmail.com

Department of Public Health, Faculty of Education, Health and Wellbeing, University of Wolverhampton WS1 3EZ, United Kingdom

Tel: +447305612279

Citation: Ekpenyong MS, Bond C, Matheson D (2019) Challenges of Maternal and Prenatal Care in Nigeria. J Intensive \& Crit Care Vol.5 No.1:6

Received: January 30, 2019; Accepted: February 20, 2019; Published: February 27, 2019

\section{Introduction}

For over a century, maternal mortality has been identified as a major global health indicator [1]. Rates of maternal mortality, like other health indicators, reflect pervasive inequalities founded on race and ethnicity. It is well documented that women of color experience disparate rates in birth outcomes in comparison to their white counterparts, which in turn has recurring implications for maternal and fetal mortality [2]. This study primarily centered on the challenges of maternal and prenatal care experienced by Nigerian women. Primary considerations for the study centered on individual and structural barriers that women experienced while accessing care. Maternal mortality rates, like other health indicators, reflect pervasive inequalities founded on race and ethnicity. It is well documented that women of color experience disparate rates in birth outcomes in comparison to their white counterparts, which in turn has recurring implications for maternal and fetal mortality [2]. Primary considerations for the study centered on individual and structural barriers that women experienced while accessing care.

High maternal and prenatal mortality is reported to be associated with lack or inadequate skilled maternal healthcare during pregnancy and childbirth particularly in sub-Saharan Africa where half (50.4\%) of all maternal deaths occur [3]. The life time risk of maternal death for a woman in sub-Saharan Africa is 332 times higher compared to a woman in the developed countries [4]. Given the above-mentioned figures on maternal death, it can be argued that maternal mortality is not evenly spread through the world's regions and is not in the same amount to the population of women of reproductive age in those regions. African countries are reported to have the highest burden of maternal mortality and sub-Saharan Africa is accountable for the depressing maternal death figure for the area, contributing 
approximately $40 \%$ of all maternal deaths due to pregnancyrelated complications which is higher in developing countries than in developed countries [3].

Improving women's health during pregnancy and childbirth has continued to be a global priority. Maternal health care is the care given to women during pregnancy, childbirth and postpartum periods to ensure good health outcomes for the woman and baby [5]. African National Congress (ANC) provide opportunity for assisting women to make birth and emergency preparedness plan [6]. However, contribution of ANC to maternal mortality reduction has been challenged. High risk screening during antenatal care as a means of identifying women for facility based delivery is not effective since most of the antenatal care provided is of poor quality in many low-income countries [7]. Factors such as poverty, inequality, poor attitude towards women and their health, cultural/traditional practices have been reported to influence the use of maternal and prenatal care in developing countries [8]. Poverty has been identified as a major barrier to human development as it makes standard healthcare excessively expensive [9].

\section{Socio-ecological approach to understanding barriers to maternal and prenatal care}

Understanding barriers to services utilization has been hindered by lack of a consistent theoretical approach that embraces a wide range of factors. The socio-ecological model (SEM) proposed by McLeroy et al. [10] is a framework which considers the dynamic interplays between the individual and the environment as the determinants of health-related behavior. McLeroy et al. [10] recommended that behavior should be incorporated in a dynamic and complex network of intrapersonal, community factors and public policy. SEM specifically considers the impact of social networks, organizational and community factors, and public policy. The analysis at this level leads to the identification of factors that influence the availability, accessibility of health care services. Humans are usually influenced most by the components of their immediate environments and exposures can shape their health behaviors. The development of poor maternal health care seeking behavior stems from multiple influences and exposures in a woman's life [11]. The socio-ecological model ranges from individual level such as socioeconomic status, knowledge, education; social environment encompasses the relationships, the culture and the society with whom the individual interacts; physical environment comprised of buildings, roads and open spaces and can provide opportunities or barriers to health [12]. The physical environment also includes natural factors such as geographical accessibility, perceived qualities of health care services; proximity to health facilities, land use, public transport and safety includes all determinants of whether women are able and permitted by their family and community to participate in outdoors activities [13]; and the policy sphere includes interpreting and implementing existing policies at the local, state, and federal governments that regulate or support social/physical environment or individual behavior, including protection of or attention to children and special populations.

\section{Aim}

The aim of this study was to explored factors influencing women utilization of maternal and prenatal care in Nigeria.

\section{Methodology}

The study was a mixed methods design that used questionnaire and in-depth interviews. The quantitative and qualitative components were implemented sequentially. The study was carried out in one of the tertiary hospitals in Delta State, Nigeria, from January to April 2015. The study participants were identified and drawn from women aged 15-49 years. This age group 15-19 years though considered under age was included in this study because of existence of teenage pregnancies that contribute to maternal mortality. Non-probability sampling method was employed for the quantitative phase. A total of 318 respondents attending the health facility for emergency care were requested to fill the questionnaires, whilst 6 interviews were held for women who were purposively selected from a large (318) quantitative respondents.

\section{Data analysis}

Quantitative data was analyzed using Statistical Package for Social Science (SPSS) version 20.0. Descriptive and inferential statistical methods were used to analyze the quantitative data. Bivariate analysis (cross tabulations), Pearson Chi-square test was utilized for categorical data and Fisher's exact test was also used where appropriate. Logistic regression was used for the multivariate analysis. Multi-variant logistic regression analyses were performed to estimate the relative influence of the independent variables on maternal health services utilization. Adjusted Odds ratios (AOR) were reported together with their $95 \%$ confidence intervals (Cls). The level of significance was taken at $P \leq 0.05$. For the qualitative data, the audio recordings were transcribed verbatim by the researcher prior to the analysis. Qualitative content analysis was done for the qualitative data.

\section{Ethics considerations}

The research received ethical approval from the University of Wolverhampton School of Health and Wellbeing Ethics Committee and approval from the Ethical Committee of the Tertiary Health Facility where this study was conducted.

\section{Results}

Results for the quantitative data were presented in five tables and a figure. Table 1 shows the information on the socio-demographic characteristics of respondents reveals that the age range of the women was $15-45$ years with a mean age as $26.4 \pm 5.4$. Majority (54.1\%) respondents were within $26-35$ years of age, while (14.5\%) representing 46 childbearing women were within the ages of 36-45+ years and above. Distribution of respondents by age clearly shows that women continue childbearing until their late 40 s.

Table 1 below also shows that majority 238 (74.8\%) of the respondents were married, while (1.9\%) were single. Evidence 
found in the literature shows that marriage is very essential in the formation of family and maternal health. The implication of the marital status distribution is that women still found themselves taking care of their pregnancy or children alone as single mothers,

Table 1 Demographic characteristic of questionnaire survey respondents.

\begin{tabular}{|c|c|c|c|c|}
\hline Characteristics & Frequency (n) & Percentage (\%) & Urban (\%) & Rural (\%) \\
\hline \multicolumn{5}{|l|}{ Age } \\
\hline $15-25$ & 100 & 31.4 & 65 & 35 \\
\hline 26-35 & 172 & 54.1 & 81.4 & 18.6 \\
\hline $36-45+$ & 46 & 14.5 & 85.2 & 14.8 \\
\hline \multicolumn{5}{|l|}{ Marital Status } \\
\hline Married & 238 & 74.8 & 79.4 & 20.6 \\
\hline Single & 64 & 20.1 & 65.6 & 34.4 \\
\hline Separated & 8 & 2.5 & 56 & 44 \\
\hline Widowed & 6 & 1.9 & - & 100 \\
\hline Divorced & 2 & 0.6 & 100 & - \\
\hline \multicolumn{5}{|l|}{ Education } \\
\hline Post-secondary & 163 & 51.3 & 90.8 & 9.2 \\
\hline Secondary & 92 & 28.9 & 76.1 & 23.9 \\
\hline Primary & 55 & 17.3 & 41.8 & 58.2 \\
\hline $\begin{array}{l}\text { No formal } \\
\text { education }\end{array}$ & 8 & 2.5 & 25 & 75 \\
\hline \multicolumn{5}{|l|}{ Occupation } \\
\hline Civil servant & 102 & 32.1 & 93.1 & 6.9 \\
\hline Traders & 65 & 20.4 & 66.2 & 33.8 \\
\hline Unemployed & 58 & 18.2 & 62.1 & 37.9 \\
\hline Student & 51 & 16 & 76.5 & 23.5 \\
\hline Artisan & 42 & 6.3 & 77.8 & 22.2 \\
\hline
\end{tabular}

separated, divorcees or widows. The distribution of respondents by educational qualification shows that half $(51.3 \%)$ respondents had completed post-secondary education, while $8(2.5 \%)$ had no formal education. The occupational information of respondents shows that 102 (32.1\%) were civil servants, while the reset belonged to other occupations.

Table 2 shows bivariate analysis of determinants of maternal health care utilization. Cross tabulations were used and Chisquare test was also checked. Marital status, Family type, monthly income and place of residence had significant association with maternal decision to seek care. A slightly higher (44.1\%) of the respondents with income level above minimum wage were more likely to make well than those with income level below minimum wage. The current study also shows that married respondents (40.8\%) were more likely to make good decision to seek care than those who were single/widowed/separated. The result shows that $(43.2 \%)$ of the respondents who live in the urban area were more likely to make good decision to seek care than those who live in the rural area ( $P$-values are included in the table below).

Table 3 shows socio-economic factors associated with maternal decision to utilize maternal health care services. Results show that mode of transportation was $(p=0.004)$ related to good maternal decision to utilized maternal health care services, with those who came on-foot having more good decision to seek care than those that came on motorized transport. The respondents were asked how long it would take for them to travel to the health facility by maternal decision to seek care. Travel time to the facility was significantly related to maternal decision to utilized maternal

Table 2 Maternal decision towards seeking care and selected individual factors.

\begin{tabular}{|c|c|c|c|c|c|c|c|}
\hline \multirow{2}{*}{ Characteristics } & \multicolumn{3}{|c|}{ Maternal Decision } & \multirow{2}{*}{ Total } & \multirow{2}{*}{$\mathbf{X} 2$} & \multirow{2}{*}{ df } & \multirow{2}{*}{$P$} \\
\hline & Poor & Fair & Good & & & & \\
\hline \multicolumn{8}{|l|}{ Marital Status } \\
\hline Married & $20(8.4)$ & $121(50.8)$ & $97(40.8)$ & 238 & 8.711 & 2 & 0.013 \\
\hline Single/widowed/separated & $8(10.0)$ & $54(67.5)$ & $18(22.5)$ & 80 & & & \\
\hline \multicolumn{8}{|l|}{ Estimated monthly income } \\
\hline Below minimum wage & $12(19.4)$ & $27(43.5)$ & $23(37.1)$ & 62 & 21.786 & 2 & 0.000 \\
\hline Above minimum wage & $4(2.2)$ & $96(53.6)$ & $79(44.1)$ & 179 & & & \\
\hline \multicolumn{8}{|l|}{ Place of residence } \\
\hline Urban & $16(6.6)$ & $122(50.2)$ & $105(43.2)$ & 243 & 24.276 & 2 & 0.000 \\
\hline Rural & $12(16.0)$ & $53(70.7)$ & 10 (13.3) & 75 & & & \\
\hline
\end{tabular}

Table 3 Association between maternal decision to seek care and socio-economic factors.

\begin{tabular}{|c|c|c|c|c|c|c|c|}
\hline \multirow[t]{2}{*}{ Characteristics } & \multicolumn{3}{|c|}{ Maternal Decision } & \multirow[t]{2}{*}{ Total } & \multirow[t]{2}{*}{$\mathbf{X 2}$} & \multirow[t]{2}{*}{ df } & \multirow[t]{2}{*}{$\mathbf{P}$} \\
\hline & Poor & Fair & Good & & & & \\
\hline \multicolumn{8}{|c|}{ Means of transportation to health facility } \\
\hline On-foot & $2(7.1)$ & $10(35.7)$ & $16(57.1)$ & 28 & 44.927 & 3 & 0 \\
\hline Motorised transport & $26(9.1)$ & $165(58.9)$ & 89 (31.8) & 280 & & & \\
\hline \multicolumn{8}{|l|}{ Travel time } \\
\hline$<30$ mins & $10(5.2)$ & $104(54.5)$ & $77(40.3)$ & 191 & 13.355 & 4 & 0.01 \\
\hline $30 \mathrm{mins}-1 \mathrm{hr}$ & $8(11.0)$ & $41(56.2)$ & $24(32.9)$ & 73 & & & \\
\hline$>1 \mathrm{hr}$ & $10(20.0)$ & $28(56.0)$ & $12(24.0)$ & 50 & & & \\
\hline \multicolumn{8}{|l|}{ Cost of Transportation } \\
\hline No cost \& 50- 100 naira & $6(6.1)$ & $49(50.0)$ & $43(43.9)$ & 98 & 32.319 & 8 & 0.003 \\
\hline$\geq 100-150$ naira & $22(10.0)$ & $126(57.3)$ & $72(32.7)$ & 220 & & & \\
\hline
\end{tabular}


health care services $(P=0.000)$, those who travelled $\leq 30 \mathrm{mins}$ were more likely to report good maternal decision compared to those who travelled more than 30 minutes. Table 3 also reveals that, cost of transportation was marginally $(\mathrm{P}=0.003)$ related to good decision making to seek maternal health care services, with those with no cost and 50-100 naira as having more good decision to seek care than those with transportation cost $\geq 100-150$ naira.

Ordinal logistic regression was used to model a relationship between the two independent factors maternal income and cost of transportation to the health facility with maternal decision as presented in Table 4. Both maternal income and cost of transportation to health facility remained predictive of maternal decision. Women with low income had lower odds of exhibiting good maternal decision compared with their counterparts who had higher income (AOR: $0.33,95 \% \mathrm{Cl}: 0.19,0.60$ ) (Table 5). Also, when the cost of getting to a health facility was low, there was a high likelihood of making good decision compared with an instance where cost of reaching a health facility is high (AOR: 2.06, $95 \% \mathrm{Cl}: 0.19,3.45)$, this was statistically significant at $\mathrm{p}<0.05$. Analysis showed that women who earned below the minimum income where surprisingly less likely to experience adverse maternal outcome (AOR: $0.69,95 \% \mathrm{Cl}: 0.24,1.97$ ) compared with those who earned more than the minimum income. With respect to history of pregnancy, loss of pregnancy in the past was a risk factor to adverse maternal outcome (AOR: 3.43, 95\% Cl: 1.41, 8.37). Quality of care at the facility had an impact on adverse maternal outcome as the likelihood of experiencing adverse maternal outcome was significantly lower when quality of care was reported to be optimal (AOR: $0.14,95 \% \mathrm{Cl}: 0.05,0.35$ ).

\section{Quality of care and pregnancy experiences at the study site}

Women's perceptions were used to identify quality of care. The following 6 Items: delay before obtaining medications, time spent on waiting to obtain medications, delay before doing lab test, time spent on waiting to get lab test done, delay in accessing treatment, time spent before treatment was administered were used to compute a summary quality of care variable in Figure 1. For each of the 6 questions, options that represented adequate quality of care received at health facility were given a score of 1 point, while inadequate options were given 0 point. Total score for overall quality of care was 6 points. Quality of care was then characterized as sub-optimal (if aggregated score $\leq 4$ ) and optimal (if aggregated score $\geq 5$ ). Of the two categories on how quality of care was experienced by the women at the health facility suggest that $(67 \%)$ respondents reported their care experience as being optimal when compared with (33\%) respondents who reported their care experience as being optimal. Maternal and fetal outcome on delivery was re-categorized as good and adverse outcome for purpose of binary logistic regression.

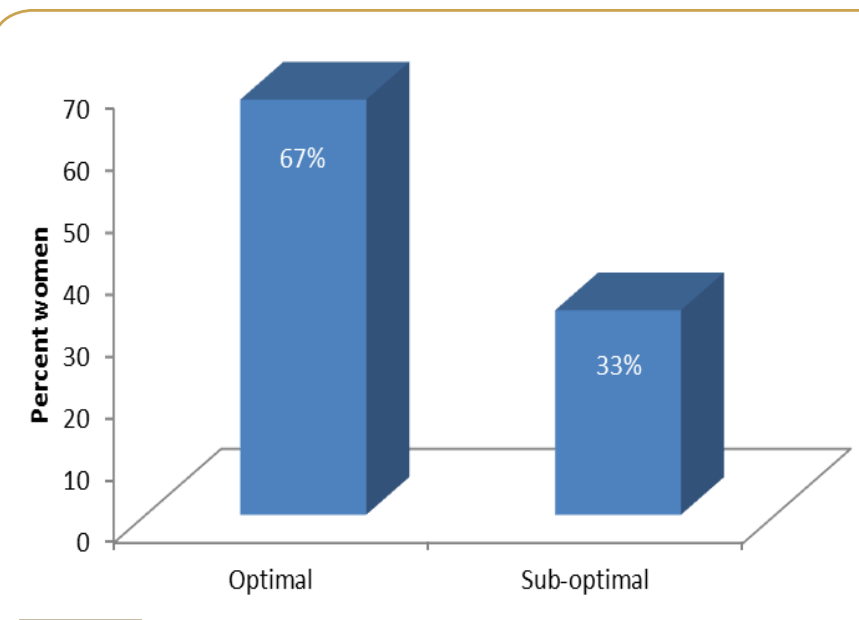

Figure 1 Percentage of women on qualitative of care from mothers' perspective.

Table 4 Results of ordinal logistic regression for factors predicting good maternal decision to seek care.

\begin{tabular}{|c|c|c|c|c|c|c|c|}
\hline & B & $(95 \% \mathrm{Cl})$ & S.E & AOR & (95\% Cl) & Wald & $\mathbf{P}$ \\
\hline \multicolumn{8}{|l|}{ Estimated monthly income } \\
\hline Below minimum wage & -1.08 & $-1.65,-0.50$ & 0.32 & 0.33 & $0.19,0.60$ & 13.533 & 0 \\
\hline Above minimum wage $(R)$ & 0 & & & 1 & & & \\
\hline \multicolumn{8}{|l|}{ Cost of transportation } \\
\hline No cost \& 50-100 naira & 0.726 & $0.20,1.24$ & 0.324 & 2.06 & $1.22,3.45$ & 7.422 & 0.006 \\
\hline$\geq 100-150$ naira $(R)$ & 0 & & & 1 & & & \\
\hline
\end{tabular}

Table 5 Adjusted for factors predicting adverse maternal outcome.

\begin{tabular}{|c|c|c|c|c|c|c|}
\hline Predictors & B & S.E & Wald & AOR & $(95 \% \mathrm{Cl})$ & $\mathbf{P}$ \\
\hline \multicolumn{7}{|l|}{ Estimated monthly income } \\
\hline Below minimum wage & - & 0.538 & 0.476 & 0.69 & $0.23,1.97$ & 0.49 \\
\hline Above minimum wage $(R)$ & 0.37 & & & 1 & & \\
\hline \multicolumn{7}{|l|}{ Ever lost pregnancy } \\
\hline Yes & 1.23 & 0.455 & 7.372 & 3.43 & $1.41,8.37$ & 0.007 \\
\hline No (R) & & & & 1 & & \\
\hline \multicolumn{7}{|l|}{ Quality of Care } \\
\hline Optimal & - & 0.472 & 17.285 & 0.14 & $0.05,0.35$ & 0 \\
\hline Sub-optimal (R) & 1.69 & & & 1 & & \\
\hline
\end{tabular}

R-Reference category, Model Chi-square=29.147, $p=0.000,-2 \log$ likelihood=134.575, Nagelkerke R2=0.232 


\section{In-depth interview findings}

Four main themes related to the participants' maternal and prenatal care experience emerged.

\section{Individual and socio-cultural barriers}

In this theme factors influencing women's decisions to seek care towards uncovering the consequence of these factors on their ability to access health care services were explored. Participants anonymously reported that individual and socio-cultural factors such as controlling behavior experienced by women impacted on women's ability to seek antenatal care in health facility. Women exclusively are the ones that get pregnant but this study reveals that most women do not participant in decision concerning their care. Such behaviors attributed to the non/underutilization of these services as was experienced by three of the participants; having a wicked mother-in-law,

"I have a very wicked mother-in-law that thinks that each time I leave the house that I go to visit other men (lovers). Because of this untrue accusation I get scared obtaining permission from her (mother-in-law) thereby not attending antenatal care".

It was consistently the case that women who had only daughters and who had no support from their spouse and other significant members of the family often do not use the services. One of the participants retreated that, "not having a male child is seen as my fault. My mother-in-law thinks because I do not position myself well during intercourse is the reason for my not having a male child for my husband". Some of the participants reported experiencing multifunctional responsibilities within the family, whilst some women reported being supported with chores by their family. One of the participants argued, "Even though I was heavy (pregnant) I still was the one doing all the domestic chores. Because I am a woman I was still expected to carry out all the work without support from the father of my children". Doing domestic work without support from my husband was also a hindrance to care" On the contrary, another participant has this to say:

".... I have money and educational influence to facilitate things for me. I have my mother and a maid in the house to help me fix all the domestics work and other things that need to be attended to in my absence".

Poverty was a common complaint among the participants as an underlying factor for non-use of skilled maternal health care services. As the participants claimed inability to afford skilled birth attendants during pregnancy and delivery. Poverty limits Nigerian women's choice and their right to access reproductive health care services. The findings of the study revealed that poverty is one of the main reasons for not seeking a skilled birth attendant and instead consulting a traditional birth attendant. Participants in the interview brought up poverty as the obstacle for seeking Maternal Health Care Services (MHCS). Interviews with the participants indicate that majority of the women were economically dependent on their spouses. Even though maternal health care services are said to be free on paper in the state where this study was conducted, transportation, medications and laboratory test were not given freely. Poverty in this study was expressed as lack of money. One of the participants argued,

"I just think every other problem is surrounded by money. When you have money, you can overcome many difficulties. With money, I can get a good health care. My sister money for me oh.... is everything".

\section{Logistic barriers}

Women face numerous problems in accessing appropriate maternity care during pregnancy and delivery. Women reported that limited or lack of public transport services and police stops make maternal health care service use difficult. Analysis of the narratives of five of the participants indicates that the logistics of the health systems of Nigeria have a lot of barriers in the form of transport services due to unavailability of fuel in the ambulance within the health systems to assist in moving patients from one facility to another. Women who were on referral from one facility to another following a complication reported that they were not provided with an ambulance for their referral. The participants noted that there is always the issue of fuel or driver to drive the ambulance to the referred facility and that in most cases, the patient is asked to fuel the vehicle. One of the participants argued,

"If there is an ambulance available in the facility the might be no fuel in it and sometimes the might suggest that the patient should buy fuel for the ambulance, and the roads condition is very bad. The problem is just too much that I can't say them all in just a day".

Cost emerged as the barrier to utilizing maternal health care services. All the participants anonymously reported that costs are a significant constraint in seeking maternal health care services during pregnancy and delivery. Women commonly reflected these views during the interviews.

"It took me almost an hour to travel down here and the transport fare is very expensive too. Also, because of the fact that transportation was too expensive for me and my mother to afford, we had to walk down here on-foot from the first hospital I went to following the bleeding I had. Everything about hospital is expensive. The drivers complained of bad road, traffic and giving bribes to the police as part of the reason they had to hike their fare". Another participant reported that: "Most drivers do not want to operate in areas with poor roads and because of this; one will have to wait for many hours before getting a vehicle".

Additional explanations were provided for the logistic barriers identified while utilizing maternal health care services. Regarding availability of services to ensure effective delivery of maternal health care services, four participants reported a common problem related to structure of services and inadequate services. Once a decision to seek care has been made, other obstacles must be overcome in reaching the facility. Overcoming transportation difficulties in the community and reaching the health facility does not mean the transportation problem is over. Four of the participants stated that some health facilities are without an ambulance and even those with an ambulance, it may be almost inaccessible at certain times. Two of the participants argued, 
"...on several occasions. Sometimes they give you the simple things they have and the major ones are not there. So, you have to go and look for them outside to buy". In the same manner, another participant has this to say: "The medical bills and medications to buy which at times you don't see it to buy from the pharmacy here in the hospital. The prices of these medications are too expensive outside the hospital environment".

\section{Healthcare incompetence}

This theme explores how healthcare incompetence can impact on participants' future behavior towards the utilization of health care services during pregnancy, labor and the immediate postpartum period. Two of the participants expressed a level of satisfaction with health care services, however most participants were not happy with health care facilities during and after delivery. The participants identified lack of management and communication skills as factors associated with health care incompetence in health facilities. When other obstacles are overcome and a pregnant/ nursing mothers and/or her new-born baby with complications reached medical facility, there may be other problems that threaten their chances of survival. The challenge of receiving prompt and appropriate care after reaching the health facility may start by not meeting the consulting physician/midwife on their duty post. The dismal story of two of the participants may illuminate the situation.

“... Most times doctors and nurses responsible for a patient's care are often not in their duty post. Sometime even when they are there, they might just be seated in their offices doing nothing. Most times you have to wait for like an hour or more before you can be attended to. I actually find this to be a very bad practice on their part". In the same manner, another participant stated that: "Agreed, that some of our hospitals are lacking in basic equipment and our health staff can be very abusive at times, they are still very safe than home delivery or mission houses".

Three women reported unofficial payments and neglect as a challenge when utilizing MHCS. Although services are said to be free to pregnant/nursing mothers on paper, giving staff incentives to get express care and healthcare staff asking women to bring things not necessary for delivery still threaten many mothers from seeking emergency obstetric care at larger facilities like the one where this study was conducted. One of the participants has this to say:

"My sister, the problem of our people is beyond poor people like us. Even if such things are available, someone of my class can never have access to it. Number one, I don't have any healthcare staff as a friend. The corruption here is too much. Everything is based on who you know, or you have money to make things work for you". On the contrary, another participant has this to say, "I have everything working out for me. Most of the health staff is my friends and I also have the money to do what is required of me".

Regarding service utilization with the health facility, it was gathered that friendliness of health care staff in providing services was a major concern that affect decision to consider service utilization of health facility on the part of the care seeker. It was argued,
"The health care staffs don't ever use words of encouragement. They are too full of themselves. They use your condition to make mockery of you. Use of abusive words is part of their services provision. I don't blame them but the country".

Participants complained about the lack in medical skills by some of the health care staff.

"The government just allowed these doctors and nurses to take laws into their hands, especially the young ones that even lack the skills and experience. Most of them, if you ask me I will say they know next to nothing other than being pompous". Another participant argued that some of the health staff who acted poorly does so because they also have their personal problems and this impacted on their job. "Let me give it to them. They tried! It's only few of them that could be nasty"

\section{Discussion}

Lack of finance was present at the individual, social and physical level in both the quantitative and qualitative findings. Financial need was identified as being a driving factor for poor decision making to seek care in health facility. Studies have consistently revealed that women's socioeconomic status underlines and shapes utilization of maternal health care services $[9,14]$. In this study, the disparities between socioeconomic status and maternal health care utilization were very clear in both quantitative and qualitative findings. This was seen with an increased likelihood of low income women exhibiting lower odds of making good decision to seek care. The mean age of respondents in the current study was $26.4 \pm 5.4$ years with an age range between 15 and 45 years. Eighteen percent of younger mothers in the current study aged 15-25 years were more likely to report poor maternal decision making in seeking care from skilled birth attendants than those 26-35 years. It could be argued that poor decision-making to seek care recorded among younger women in the current study could be due to lack of financial autonomy and seeking husband's approval or other significant person before accessing care. This finding agrees with the finding of Chakraborty et al. [15] and Tsawe et al. [16] found that non-use of maternal healthcare services was highest among mothers who were under the aged of 20 years than those who were $20-34$ years.

Both quantitative and qualitative findings reveal that cost of transportation particularly during emergency was reported as the reasons for delays in deciding to utilize health facilities for maternity care, particularly among women who were unemployed. This finding was resonated in the study by Oiyemhonlan et al. [17] on men's involvement in care and support during pregnancy highlighted that many of the women did not have readily available transportation to come to the hospital in the event of an emergency. The study findings regarding distance as highlighted by most of the women (both in the quantitative and qualitative findings) utilized health care facilities due to proximity. Holmes and Kennedy [18] explained that long distances from home to the nearest facility and between health facilities add greatly to delays in reaching emergency obstetric care. The quality of care and pregnancy experiences at the healthcare facility in the quantitative finding was reported to be optimal by $67 \%$ of respondents compared to $33 \%$ who reported sub-optimal. 
A high level of dissatisfaction on the management, communication and clinical skills was observed. Onah et al. [19] study on patients' perception of actual care conditions and patient satisfaction with care quality in hospital stated that the overall view of patients' perceptions of quality of care mostly was good and that patient satisfaction was high. Participants acknowledged that unsatisfactory attitude of health care providers lead to the continued delay and underutilization of health care facilities for care among Nigerian women. Corruption in the current study appeared as one of the factors that affects women's access to, and use of maternal health care services. This study, like many before it $[20,21]$ has highlighted the impact of corruption on healthcare utilization.

\section{Limitations of the Study}

The views of participants who did not attend the facility for care/ delivery were not represented in this study because they could not be accessed and therefore did not participate in the study. This

\section{References}

1 Storeng KT, Behague DP (2017) "Guilty until proven innocent": The contested use of maternal mortality indicators in global health. Crit Public Health 27: 163-176.

2 Rankin KM, David RJ, Collins JW Jr (2011) African American women's exposure to interpersonal racial discrimination in public settings and preterm birth: the effect of coping behaviors. Ethn Dis 21: 370-376.

3 Esena RK, Sappor MM (2013) Factors associated with the utilisation of skilled delivery services in the Ga East municipality of Ghana part 2: Barriers to skilled delivery. International Journal of Scientific and Technology Research 2: 195-207.

4 Shah IH, Say L (2007) Maternal mortality and maternity care from 1990 to 2005: uneven but important gains. Reprod Health Matters 15: 17-27.

5 Hounton S, Chapman G, Menten J, De Brouwere V, Ensor T, et al. (2008) Accessibility and utilisation of delivery care within a Skilled Care Initiative in rural Burkina Faso. Trop Med Int Health 13: 44-52.

6 World Health Organization (1994) The mother-baby package: WHO's guide to saving women's and infants' lives. Safe Mother, pp: 4-7.

7 Penn-Kekana L, McPake B, Parkhurst J (2007) Improving maternal health: getting what works to happen. Reprod Health Matters 15: 28-37.

8 United Nations Children Education Fund (2008) Report highlights risks of maternal mortality in developing world.

9 Babalola S, Fatusi A (2009) Determinants of use of maternal health services in Nigeria--looking beyond individual and household factors. BMC Pregnancy Childbirth 9: 43.

10 McLeroy KR, Bibeau D, Steckler A, Glanz K (1988) An ecological perspective on health promotion programs. Health Educ Q 15: 351-77.

11 Brindis CD, Sattley D, Mamo L (2005) From Theory to Action: Frameworks for Implementing Community-Wide Adolescent Pregnancy Prevention Strategies. Bixby Center suggests the need for large scale study which is representative of the entire population of women of reproductive age and which seeks the view of women of reproductive age accessing care in hospitals alongside those outside the health facility as their experiences could be different.

\section{Conclusion}

This study has shown that mothers in this region where the study was conducted were not significantly utilizing health facility for skilled birth attendants during pregnancy and delivery care. The study results also highlighted the need for improvement to promote present and future health care utilization. The findings based on the view of the study informants indicated many issues that should be improved upon for better utilization of health care services. These issues include: training of more health staff to eliminate long waiting hours, needed health equipment should be provided and health care staff to change their unprofessional attitude towards patients.

for Reproductive Health Research and Policy, University of California, San Francisco, pp: 1-74.

12 Tappe KA, Glanz K, Sallis JF, Zhou C, Saelens BE (2013) Children's physical activity and parents' perception of the neighborhood environment: neighborhood impact on kids study. Int J Behav Nutr Phys Act 10: 39.

13 Giles-Corti B, Kelty SF, Zubrick SR, Villanueva KP (2009) Encouraging walking for transport and physical activity in children and adolescents: how important is the built environment? Sports Med 39: 995-1009.

14 Mekonnen Y, Mekonnen A (2002) Utilization of Maternal Health Care Services in Ethiopia. Calverton, Maryland, USA: ORC Macro, pp: 1-25.

15 Chakraborty N, Islam MA, Chowdhury RI, Bari W (2002) Utilisation of postnatal care in Bangladesh: evidence from a longitudinal study. Health Soc Care Community 10: 492-502.

16 Tsawe M, Moto A, Netshivhera T, Ralesego L, Nyathi C, et al. (2015) Factors influencing the use of maternal healthcare services and childhood immunization in Swaziland. Int J Equity Health 14: 32.

17 Oiyemhonlan B, Udofia E, Punguyire D (2013) Identifying obstetrical emergencies at Kintampo Municipal Hospital: a perspective from pregnant women and nursing midwives. Afr J Reprod Health 17: 129-140.

18 Holmes W, Kennedy E (2010) Reaching emergency obstetric care: overcoming the 'second delay'. Burnet Institute on behalf of Compass, the Women's and Children's Health Knowledge Hub. Melbourne, Australia.

19 Onah HE, Ikeako LC, lloabachie GC (2006) Factors associated with the use of maternity services in Enugu, southeastern Nigeria. Soc Sci Med 63: 1870-1878.

20 Paredes-Solís S, Andersson N, Ledogar RJ, Cockcroft A (2011) Use of social audits to examine unofficial payments in government health services: experience in South Asia, Africa, and Europe. BMC Health Serv Res 11: S12.

21 Jain A, Nundy S, Abbasi K (2014) Corruption: medicine's dirty open secret. BMJ 348: g4184. 